\title{
Analysis on Supplementary Education of Contemporary Colleges under Functionalism Perspective
}

\author{
Tingting $\mathrm{Wu}$ \\ School of Humanities, Xi'an University, Xi'an, Shaanxi 710065
}

Keywords: Functionalism; Colleges; Supplementary education

\begin{abstract}
Supplementary education of colleges is a special form of supplementary education, which, as an important content and phenomenological representation in the reform and development of contemporary Chinese education, generates double influences on traditional higher education system. Supplementary education of colleges in the trend of normalization, specification and utilitarianism reflects the problems existing in the development of higher education in contemporary China deeply. This paper analyzes the rational basis of existence of supplementary education of colleges from the perspective of functionalism through analysis on the supplementary education phenomenon of contemporary Chinese colleges; carries out reflection and summary of the existing problems; and puts forward that correct guidance, government specification and benign complementary mechanism are the basic paths of developing supplementary education of colleges.

As a notable characteristic of contemporary Chinese education, supplementary education is the extension and supplement of formal education, and also the product of China's development in politics, economy and culture. "From the history of higher education, remedial course can be traced back to the United States in the $17^{\text {th }}$ century." ${ }^{[1]}$ There are many studies on the issue abroad; while the discussion about supplementary education in China mainly focuses on primary \& secondary school education and preschool education, without much discussion about adult supplementary education. College stage is an important period of choosing the development mode in future with self-development as the premise and destination; and various forms of supplementary education which are freely selected other than formal college education constitute the basic pattern of supplementary education of contemporary colleges based on acquisition of various qualifications, demand of future vocation and realization of life goals. The structure of teachers in supplementary education has been developed to institutional "professional team" system from original informal employment system, and many college teachers and scientific researchers participate in the team. Current situation of supplementary education of colleges is as follows: any young person who is in need of learning can find suitable training school and related courses in the market. Thus, the development of supplementary education of colleges is in direct proportion to China's economic development and cultural industry updating to a certain extent.
\end{abstract}

Supplementary education of colleges in China undergoes a process from weak initiation, imperfect system and single variety to rapid development, complete system and wide varieties, which has become a non-negligible education phenomenon. However, through complex phenomenon of supplementary education, we deeply realize the impediment to formal higher education, adult success and educational fairness. As an important functionalism of educational sociology school, its main research direction is to discuss macroscopic education from the perspective of sociology, so as to maintain social balance and promote social development. This paper carries out analysis on supplementary education phenomenon of colleges based upon functionalism, and then realizes its reasonable basis and existing problems rationally.

\section{Supplementary Education of Colleges and the Features Thereof}

Supplementary education refers to systematic learning activities like tutoring which are taken by various education objects to meet their cultural or artistic demands aside from formal education. ${ }^{2]}$ Therefore, supplementary education of colleges refers to systematic learning activities such as tutoring and training which are taken aside from formal higher education, oriented around cultural development demand and employment $\&$ careers, and generated towards specific education objects 
-- college students.

Supplementary education in contemporary China focuses on the supplementary education at basic education and preschool education stages; while supplementary education of colleges is often neglected due to adult educatee as the object, and the latter has the following characteristics in comparison with the former:

As the Participants, College Students Have Self-Consciousness. Adult participants are goal-oriented when choosing further learning, who have self-consciousness in comparison with basic education objects. Self-consciousness of the adult education and directness of subject selection make the educatee learn actively, which is an impetus for supplementary education to receive obvious teaching effect within a short period. But formal education is compulsory, which is featured with long learning cycle and indirect effect.

College Students Have Relatively Flexible Time and Energy, Which Makes Them Initiative to Choose Supplementary Education. College students can choose suitable tutoring form as they wish according to their own development demand, and they are free in comparison with those who receive basic education with only one purpose of entering a school of a higher grade.

Supplementary Education of Colleges Is Based on Purpose or Utilitarianism of Career Choice. As for utilitarianism, both the supplementary education of colleges and that of basic education perform significantly; and the difference is that the former refers to pre-service preparation, while the latter is less related to employment.

In current stage, supplementary education extends the period and range of higher education comprehensively, which not only provides success opportunity, guarantee and conditions for college students, but also relieves the employment pressure of China to a certain degree.

Timely and Appropriate Supplementary Education of Colleges Promotes and Supplements Formal Higher Education

"Full development and maturity of adult education are essential for lifelong education development."[3] Supplementary education of colleges promotes the building, development and improvement of lifelong education system.

Supplementary education of colleges promotes the role conversion from student to social person. Supplementary education pays more attention to the practical need of students in future development, thus shortening the gap between individual and the society to a certain extent.

Supplementary education of colleges creates rich and diversified teaching resources, educational situations and teaching contents in different scales and special modes, which makes up for the deficiency of higher education.

"Richard Arum and Josipa Roksa point out in the latest book Academically Adrift: Limited Learning on College Cam puses that, there is a severe problem in current colleges, college has become a land of pleasure, and students have little improvement in learning key skills."[4] Apparently, supplementary education of colleges, as the adult education form, provides supplementation, extension and expansion for higher education to a certain degree.

\section{Degree \\ Supplementary Education of Colleges Impedes Formal Higher Education to a Certain}

"Although researchers think that participation in supplementary education plays an active role in adapting to college life, improving cognitive validity and promoting academic success"[5], the impediment of supplementary education shall not be neglected if its development mode, system setting and management are not guided in a correct way. Maybe supplementary education is the result of "market selection", but such selection is not unnormalized or arbitrary, only correct guidance and normalization can make supplementary education give full play to its advantages and eliminate its shortcomings, so that supplementary education can get into the entire education environment and system, and then become a beneficial form of adult education and necessary supplement to higher education.

Development of supplementary education of colleges provokes conflict inside school education system. In recent years, many college teachers participate in the teaching team of supplementary education, which weakens the technicality and freedom of formal college education to a certain 
extent.

Supplementary education of colleges will influence the fairness of macroscopic education. It is difficult for poor families to provide their children with supplementary education resources aside from formal education, thus causing education unfairness from unfair resource allocation.

The impact on existing higher education policy in China from supplementary education of colleges generates new problems. Firstly, how is the educational investment utilized effectively from the whole range? Secondly, how can supplementary education and formal education realize a harmonized relationship and achieve mutual complement and promotion?

Facing the shortcomings of contemporary college education, how to make supplementary education become effective supplement to not only enhance students' knowledge and capability, but also set up correct values and outlook on life has become a primary issue to guide the development of supplementary education, normalize its development direction, and promote the improvement of higher education quality.

\section{Functionalism and Its Applicability to Supplementary Education of Colleges}

"Functionalism arose from organicism in the early $19^{\text {th }}$ century." ${ }^{[6]}$ After being enriched by Herbert Spencer, the British social theorist, it was developed in America in the 1950s, with the representative theory of structural functionalism: The significance of school lies in becoming the middle link between family and vocational development, which is representative in modern environmental socialization. The basic view of functionalism is that education has two functions, which are respectively socialization and selection, that is, on the one hand, education provides social integration; on the other hand, it promotes social differentiation and division of labor. And the applicability of functionalism to educational function is mainly embodied in the following aspects:

\section{Promote the Selection of Knowledge}

In the view of functionalism, "education aims to impart specialized knowledge and skill of a corresponding field through special course according to the interests, hobbies and special talents of members of society."[7] With the modernization of society, people select and receive various educations to constantly adapt to developed society, so as to participate in human social activities meaningfully.

\section{Promote Social Mobility}

Functionalism emphasizes that members of society shall accept the "existence and rationality of social differences" and then obtain corresponding social roles and recognition by receiving education, so as to make the consciousness of social participation be "encouraged". Only human's socialization is the complete development process and the success process of a person. Acceptation and acknowledgement by the society can be regarded as one of the marks of judging whether the individual development is complete.

\section{Promote Human's Socialization}

Functionalism representative Talcott Parsons thought, "The society is composed of individual system, cultural system and social system; school and family belongs to important social system, and school is an 'important medium' of individual socialization." ${ }^{[8]}$ Apparently, education rationalizes the values and moral standards which are observed by the society, so as to promote human's socialization. And supplementary education embodies such function beyond formal education.

\section{Functionalism-based Analysis on supplementary Education of Colleges}

Since the reform and opening-up, especially in recent 20 years, the booming development of supplementary education of colleges has become a non-negligible education phenomenon, thus being analyzed by various educational theories. The perspective of functionalism is capable of providing more practical and direct advices for the balanced development of higher education.

Rationality of Supplementary Education of Colleges Under Functionalism Perspective

Throughout various kinds of supplementary education of colleges, it can be easily found that 
supplementary education of colleges is more diversified than formal classroom teaching, the former is customized for students according to their survival and development needs, with rich \& colorful content and specific goals, thus featuring large flexibility in comparison with classroom teaching; although productive supplementary education is somewhat utilitarian, its practical value exists at the same time. In this sense, supplementary education of colleges is completed in the process of converting passive learning to active learning based on that college students actively think about individual development and coordinating social development demand under adults' self-consciousness. Such educational mode shortens the process of individual socialization in conversion from student identity to professional identity, and reflects the socialization during school.

\section{Objection to Supplementary Education of Colleges Under Functionalism Perspective}

Functionalism also criticizes and avoids the educational thought and pursuit of utilitarianism. Education is a social undertaking concerning human ideals and values, which goes beyond the utilitarian value essentially; however, supplementary education is featured with obvious utilitarianism. On the one hand, the appointed teachers (including college teachers) who engage in supplementary education of colleges aim to get income; on the other hand, the students who receive supplementary education of colleges aim to choose a better job through obtaining a certain qualification or mastering a skill. The concepts of learning and lifelong learning are misconstrued, which become the means of gaining benefit. In supplementary education, there is an obvious economic relationship between college students (educatees) and supplementary schools (educators). In the process of supplementary education, the relationship between teachers and students is challenged, the role of teachers with knowledge authority is weakened, instead, the employment relationship is obvious; students just learn the knowledge that they pay for, while teachers' inner cultivation and virtue are covered and ignored, all of which are adverse for students to acquire true and pure teaching process, and it is hard to realize that "teaching is learning". Therefore, supplementary education of colleges is characterized by freedom, imbalance and utilitarianism, which somewhat deviates from the basic keystone of functionalism.

\section{Conclusion}

In summary, supplementary education of colleges is a special form of supplementary education, which, as an important content and phenomenological representation in the reform and development of contemporary Chinese education, generates double influences on traditional higher education system. "Individuals hope to reinvent themselves and change their destinies through education; and the society takes educational institution as the cradle of talents." ${ }^{[9]}$ Supplementary education of colleges in the trend of normalization, specification and utilitarianism reflects the problems existing in the development of higher education in contemporary China deeply; from the view of educational principle, its development reflects that Chinese people have gradually enlarged the demands of improving individual comprehensive quality since economic development. Functionalists believe that supplementary education of colleges at current stage generates both positive and negative influences. Supplementary education enlarges the educatees' freedom of choosing education variety and type, which is consistent to the basic argument of functionalism. However, current supplementary education of colleges is featured with utilitarianism, disorder and conflict with formal higher education, which deviates from basic requirement of functionalism, generates impact on existing education system, and gives rise to the waste of educational resources and the diversion of educatees' energy. The author thinks it is required to fully study the basic characteristics of supplementary education of colleges, and issue related supervisory strategies and schemes for supplementary education of colleges in combination with current situation of supplementary education of colleges from the perspective of functionalist education principle, so as to maximize its advantages, make sure it supplements existing higher education, perfect existing higher education system in China, realize mutual promotion and benefit between higher education and supplementary education of colleges, and promote common development. Only in this way can "adults be educated for free, and teachers be accomplished without schools." [10] 


\section{Acknowledgments}

(This paper is the phased achievement of Shaanxi Province education science planning topic "Interpretation of Traditional Culture in Chinese Textbooks and Research on Teaching Practice by Chinese Teachers in Primary and Secondary Schools of Shaanxi Province". Achievement No.: SGH17H246.)

\section{Author}

Wu Tingting (1979-), female, born in Xi'an, Shaanxi, doctor of science in education and associate professor, with the research direction of educational principle.

\section{References}

[1] Tang Yang, Zhang Guang, Liu Chengbin, et al. International Experience of Remedial Course and Its Apocalypse for Continuing Education of Colleges in China [J]. Modern University Education. 2015(5):92-96.

[2] Wang Yousheng. Supplementary Education: A non-negligible educational phenomenon [J]. Shanghai Academy of Educational Sciences. 2007(6):18-24.

[3] Zheng Shaojun, Wu Shijun. Exploration on Adult Education in Taiwan [J]. Modern Science. 2007(24):208-281.

[4] [U.S.] Hu Shouping, Mei Hong. Challenges Facing U.S. Education in $21^{\text {st }}$ Century [J]. Journal of Xinjiang Normal University (Philosophy and Social Sciences). 2015(2):124-132.

[5]Bell.N.,Irvin,M.,Sweeney.A.Living the Mission: Knowing Your Students and Tracking Milestones Toward Student Success at Nashville State Community College, Leadership Policy and Organizations Department Capstone Project [EB/OL]. 2014-06-20. http://hdl.handle.net/1803/ 5311.

[6] Wang Liyun. Functionalism Tradition and the Comparative Education Methodology [J]. Comparative Education Review. 2009(4):18-22.

[7] Zhang Junhao. The Theory of Functionalism and Its Application in Education [J]. Journal of Hubei Institute for Nationalities (Philosophy and Social Sciences). 2004(6):65-69.

[8] Lan Xiuhua. Analysis of the Views of Talcatt Parsons and Randall Collins [J]. Research in Teaching. 2003(1):14-16.

[9] Mei Hong, Song Xiaoping. Basic Purpose and Realization of College Education -Comprehensive Development from U.S. General Education to "Social Person". Higher Education Exploration. 2014(2):62-67

[10] Jiang Hengyuan. Opinions on Supplementary Education of Adults [J]. Education and Vocation. 1929(109):1462-1463. 